\title{
Translocation of pocketed orang-utans in Sabah
}

\author{
Patrick Mahedi Andau, Lim Khun Hiong and John B. Sale
}

\begin{abstract}
Sabah is faced with a problem of small groups of orang-utans isolated from their parent populations in fragments of secondary forest, mainly on oil-palm plantations. The Wildlife Department has recently captured 84 such animals in three locations and translocated most of them to Tabin Wildlife Reserve, which already has a low-density population of orang-utans. The majority of animals were captured by drug immobilization, using a 5:1 ketamine/xylazine mixture at a mean dosage of $8.47 \mathrm{mg} / \mathrm{kg}$ body weight (range 3.76-22.64 $\mathrm{mg} / \mathrm{kg}$ ). This proved an effective and safe method. Others, mainly immatures, were captured manually. Few injuries or other problems were encountered. The cost of the rescue operations was \$US175 per animal. A satisfactory way of monitoring the released orangutans is under development.
\end{abstract}

\section{Introduction}

The orang-utan Pongo pygmaeus is confined to the islands of Sumatra and Borneo. The Malaysian State of Sabah occupies an area of approximately $74,000 \mathrm{sq} \mathrm{km}$ on the northern tip of Borneo and had an estimated population of the Bornean subspecies, $P$. pygmaeus pygmaeus, of 10,000-20,000 in 1988 (Payne, 1988), although this has probably declined by several thousands in recent years (J. Payne, pers. comm.). The majority occur in lowland dipterocarp forests of eastern Sabah at densities of $1.2-3.0 / \mathrm{sq} \mathrm{km}$ irrespective of whether or not the forests have been logged for commercial timber (Payne, 1988). Loss and fragmentation of forest habitat through permanent conversion to oil-palm plantations is by far the most serious threat and frequently results in isolated pockets of orang-utans cut off from the main populations in uncleared forest reserves. Thirty per cent of Sabah's land area is deemed suitable for agriculture and the area under agricultural plantations is increasing rapidly, especially in the eastern lowlands.

Previously logged 'secondary' forest is cleared for planting by felling the larger trees and then bulldozing and burning the remain- ing vegetation. Orang-utans living in a remnant patch of forest that is being cleared by this process are thus subjected to enormous stress from rapidly disintegrating habitat, noisy humans and their machinery, and flames and smoke from the torched vegetation.

Apart from long-term reproductive isolation the survival of pocketed groups of orangutans is jeopardized by a scarcity of natural food and trees for overnight nests, harassment by plantation labourers and domestic dogs, and ill-health resulting from stress and inadequate nutrition. The apes become unpopular with plantation managers when they resort to damaging oil-palm seedlings in search of food. If left indefinitely, the animals will progressively succumb. Situations of this kind leave the management authority with a dilemma, especially because the conservation value of translocating primates is sometimes questioned (Caldecott and Kavanagh, 1983). The only acceptable solution in such cases is a 'compassionate' translocation to a well-protected area with suitable habitat, providing that a reliable capture method is available (Payne, 1988). This paper presents the first reported orang-utan translocation of this kind, carried out by the Sabah Wildlife Department 


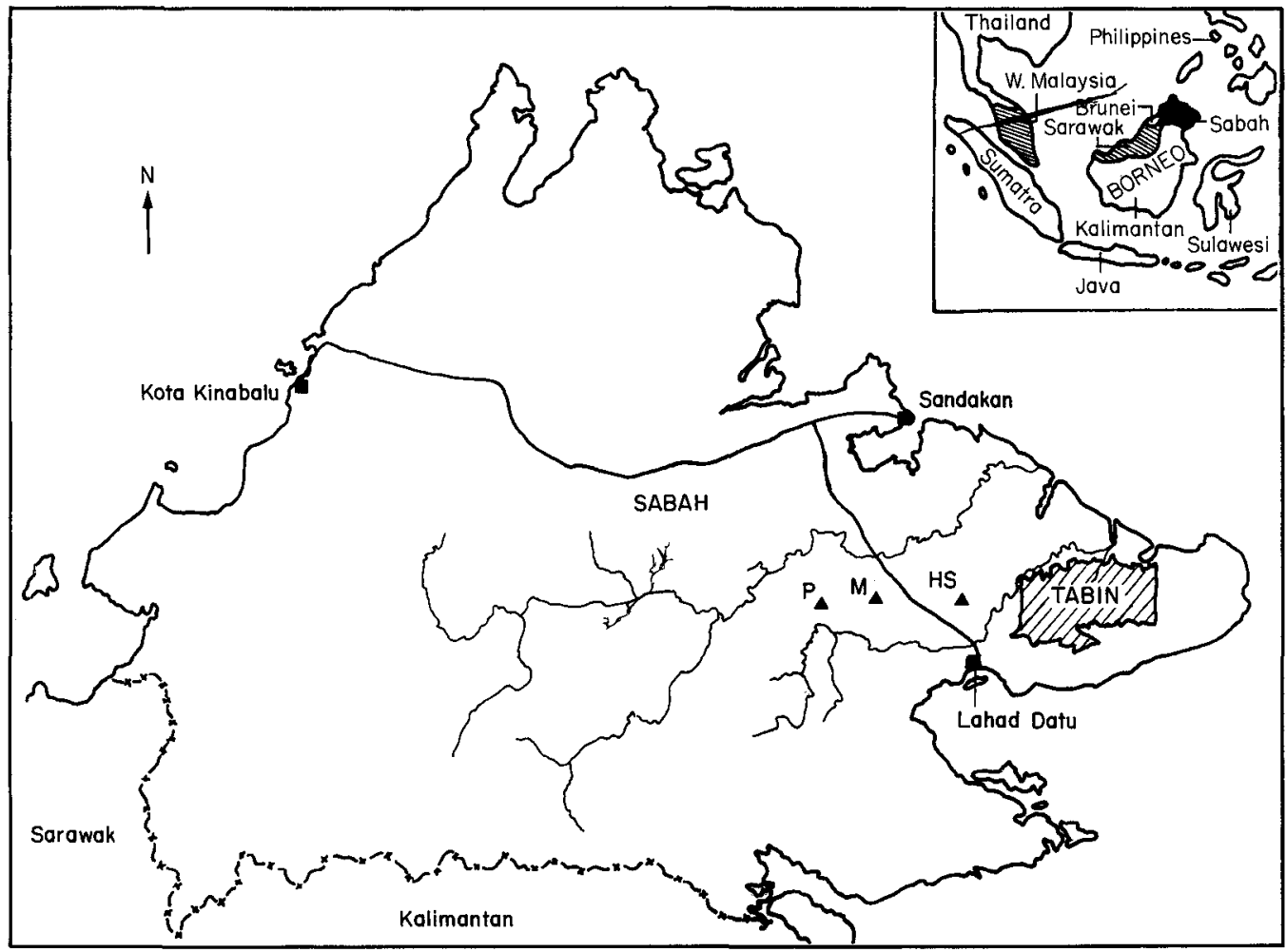

Figure 1. Map showing location of Tabin Wildlife Reserve in relation to the three capture sites (HS, Hang Sam; M, Mewah; P, Pintasan).

between June and September 1993.

\section{Capture and release locations}

Three capture locations, all on developing oil palm plantations in the Kinabatangan District of eastern Sabah, were involved. All translocated animals were released in Tabin Wildlife Reserve between 40 and $70 \mathrm{~km}$ east of the capture sites (Figure 1).

The first batch of orang-utans was captured between 17 and 25 June 1993 while tree felling was in progress in an isolated forest of approximately $40 \mathrm{ha}$ on the Hang Sam Plantation. In addition to the orang-utans, the area contained several other primate species, deer and more than 50 species of birds. In a second phase ( 28 June- 6 July) further animals, confined to fallen trees and tangled under- growth, were captured near the ground. A few stragglers were picked up later (23-26 July) among the still burning remains of the vegetation. At Mewah Plantation a few orangutans were captured between 14 and 22 July. These animals were living in an area totally cleared of trees 1 year previously. Due to a scarcity of natural food they were feeding on newly planted palm seedlings, 120 of which had been totally destroyed.

At the 3400-ha Pintasan Plantation orangutans were removed in two phases (16-25 August and 3-25 September) from some 20 remnant patches of forest under current clearance and ranging from 2 to 12 ha in area.

The 120,000-ha Tabin Reserve is Sabah's largest wildlife reserve and its management is being currently upgraded according to a management plan prepared with the assistance of a UNDP adviser attached to the Wildlife 
Department. It is one of the best protected areas with lowland dipterocarp forest in Sabah at present and has a viable population of orang-utans in its more remote eastern sector. The western sector, which has similar habitat, has only a few orang-utans, possibly as a result of heavy hunting in former times. There has been no evidence of hunting in recent years, however. The presence of appropriate food trees and some orang-utans was taken as provisional confirmation of the suitability of the area for the species and all releases were made in western Tabin. A detailed study of food availability was not possible prior to the emergency translocations but this will be carried out concurrently with monitoring of the released animals.

\section{Methods}

The majority of animals were captured by some form of drug immobilization but some were captured by hand at ground level. In a typical operation an orang-utan was darted some $15 \mathrm{~m}$ up a tree and on immobilization fell in stages through a tangle of vines to the ground. In the absence of natural cushioning to break the fall, a net was held out about $1 \mathrm{~m}$ above the ground to catch the animal. After veterinary examination, the new captive was carried on a sack slung from a pole on the shoulders of two workers to the base camp. There it was weighed, and blood, hair and faecal samples taken. It was then placed alone in a metal barred cage $(90 \times 60 \times 90 \mathrm{~cm})$ in deep shade pending recovery, during which time body temperature and other vital signs were monitored by the veterinarian. Animals that showed signs of rising temperature were cooled by showering and given an injection of antidote (see below). Food and water were offered, and normally taken, after full recovery.

For the great majority of immobilizations, a drug mixture containing ketamine (Ketalar, Parke Davis) and xylazine (Rompun, Bayer) in a ratio of 5:1 was used, at a dosage rate of 5 mg ketamine and $1 \mathrm{mg}$ xylazine $/ \mathrm{kg}$ estimated body weight. Where rapid recovery from this mixture was desirable, the xylazine antidote

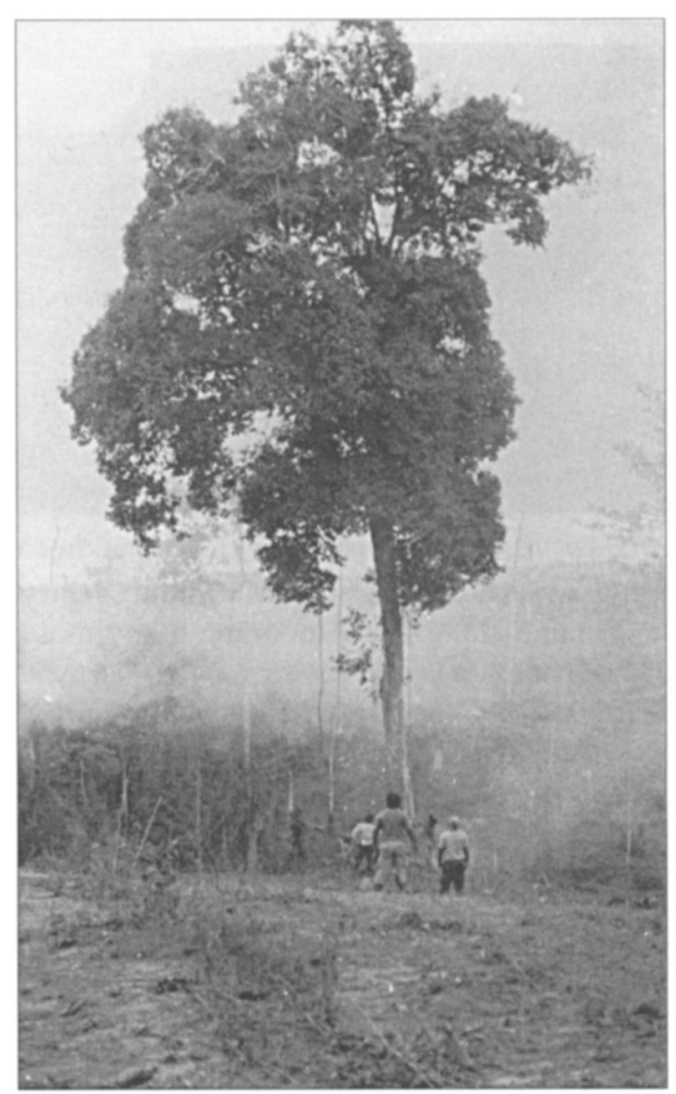

A single tree, containing an orang-utan awaiting rescue, about to be felled amid smoke from nearby burning vegetation.

yohimbine hydrochloride (Reverzine, Parnell) was administered intravenously by hand. In a few cases use was made of the alternative drug Zoletil (Virbac), containing tiletamine and zolazepam in 1:1 ratio, at a dosage rate of $2.5 \mathrm{mg}$ tiletamine and $2.5 \mathrm{mg}$ zolazepam $/ \mathrm{kg}$ body weight.

Two systems for remote delivery of the drug into the animal were employed. The preferred system was the Telinject air-powered rifle and 1- or 3-ml plastic darts activated by air pressure. This is relatively silent in use and inflicts minimum trauma to the animal due to low velocity and the light weight of the dart. It is also relatively inexpensive. As a back-up, the powder-charged Distinject system, with either disposable plastic darts or metal darts, was used. This gun is not silent and the 


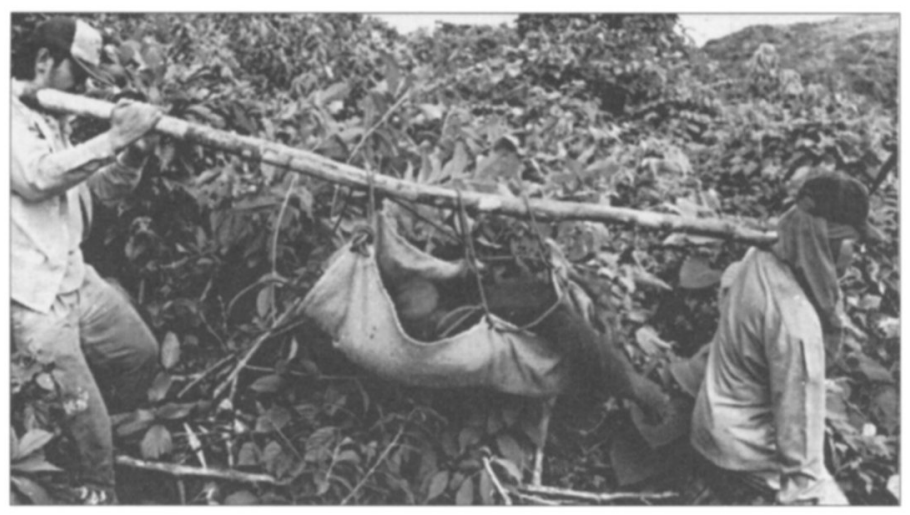

An immobilized animal is carried out of the jungle to an awaiting vehicle. heavier metal darts are liable to inflict injury on a mammal the size of an orang-utan should a shot have too much power for the distance. A 19- or 20-mm needle, with a retaining collar, was found to be optimal in both systems.

Transport to Tabin, from 2 to 3.5 hours distant depending on capture site, took place during the cooler parts of the day, normally on a daily basis. Cages were placed on a flat truck or pick-up and shaded with foliage or sacking sprinkled with water to provide a cooling effect. At the individual release sites, which were a minimum of $1 \mathrm{~km}$ apart, a single cage door was opened, allowing the inmate to move freely into the forest at its own pace.

\section{Results}

In the 3-month period of operations, 84 orangutans were captured at the three locations. Of these, 48 were immobilized by darting, either in trees or on the ground. A further 14 were immobilized by hand injection after partial restraint on the ground, while 22 (mainly immatures) were captured manually, sometimes with the aid of a net but without administration of any drug.

Fifty-four of the animals captured were adults, estimated to be 7 years old and above (20 males; 34 females). The remainder were immature animals up to 6 years old ( 6 males; 24 females). The mean body weight of adult males was $37 \mathrm{~kg}$ (range 15-72) and of females $27 \mathrm{~kg}$ (range 14-36). Immature weights ranged from 2.5 to $17.5 \mathrm{~kg}$. The majority of orang- utans captured appeared to be in good health, except at Pintasan, where many of the animals were in an emaciated condition and showed signs of dehydration.

Of the total of 62 animals whose capture involved drug immobilization, 57 received the 5:1 ketamine/xylazine mixture and 5 the Zoletil mixture. The mean dosage of ketamine/xylazine actually received, based on subsequent weighing of the captured animals, was $8.47 \mathrm{mg}$ for the two drugs combined or $7.06 \mathrm{mg}$ ketamine and $1.41 \mathrm{mg}$ xylazine $/ \mathrm{kg}$ body weight (ranges: combined 3.76-22.64 mg; ketamine 3.13-18.87 $\mathrm{mg}$; xylazine $0.63-3.77$ $\mathrm{mg}$ ). The mean dosage of Zoletil was $6.90 \mathrm{mg}$ (combined) or $3.45 \mathrm{mg}$ tiletamine and $3.45 \mathrm{mg}$ zolazepam $/ \mathrm{kg}$ body weight (range: $2.35-4.55$ $\mathrm{mg}$ of each drug). The mean induction time (darting to complete immobilization) was 4.38 minutes for animals that received a single dose and 15.67 minutes for those that required two or more doses to effect immobilization. Mean recovery time (darting to initial signs of body movement) without the use of a reversing agent was 42 minutes with the xylazine/ ketamine mixture and slightly longer for Zoletil. The reversing agent yohombine was used on 10 occasions to speed recovery from the effects of the ketamine/xylazine mixture.

Of the 84 orang-utans captured, 74 were translocated to Tabin. There were no mechanical injuries resulting from the capture, handling or transport of animals. Three animals sustained minor injuries through a dart straying into a non-muscular area of the anatomy; all were treated successfully. One animal was 
found to have an unhealed limb fracture from an earlier accident and was sent to the clinic at the Sepilok Orang-utan Rehabilitation Centre for treatment. Three orphaned infants were sent to Sepilok for rehabilitation into the wild (otherwise impossible in the absence of the mother).

There were two fatalities. One was due to sun-stroke, which resulted from the immobilized animal remaining in a high nest fully exposed to the sun from which it proved impossible to remove it before excessive exposure had occurred. The second was a nursing infant, which accidentally received the dart aimed at its mother who moved as the shot was fired, and was thus subjected to four times the mean dosage rate. Four animals escaped while held in insecure temporary accommodation due to capture operations getting ahead of cage availability.

Early in the operations two forms of socially inflicted injury were observed. Mothers held in a cage with their dependent juveniles sometimes molested them, with potential to cause serious injury, although none was actually inflicted. In addition, adults occasionally seized and viciously bit the fingers of other adults in closely adjacent cages, inflicting deep lacerations. To prevent these social injuries, which presumably arose from the stressed condition of the newly captured animals, care was taken to (a) keep females in separate (but adjacent) cages from their offspring, and (b) ensure that adequate space was maintained between occupied cages, especially during transportation.

Apart from the initial social injuries noted above, transportation and release were without incident. All animals travelled quietly and left their opened cages at the release site quickly, making for nearby trees, which in most cases they climbed immediately. Early feeding activity was noted in some cases.

Increased numbers of nests were soon noted in the release area and provide a regular basis for monitoring the dispersal pattern of the released orang-utans in western Tabin.

The cost of these three operations, including manpower, fuel, drugs and expendable equipment, worked out at \$M(Malaysian Dollars) 444 ( $\$$ US175 or $£ 117$ ) per animal.

\section{Discussion and conclusions}

Overall, the procedures adopted provided a satisfactory approach to orang-utan capture and translocation and facilitated a solution to the problem of pocketed animals that have become cut off from the main population.

For individuals in trees or adults on the ground, which cannot be captured without additional restraint, drug immobilization proved an effective and reliable mode of capture. In particular, the 5:1 ketamine/xylazine mixture, used at the dosage for the two drugs combined of $3.76-22.64 \mathrm{mg} / \mathrm{kg}$ body weight, was extremely safe. Apart from the infant that accidentally received an adult dose, there were no overdose fatalities among the 57 animals that received this combination, in spite of the very wide dosage range. The mixture possesses the advantage that there is an antidote, should it be perceived as having an adverse effect on the recipient.

The fact that the actual mean dosage of the ketamine/xylazine mixture used was 48 per cent higher than the dosage calculated on estimated body weights of animals (prior to capture and weighing) indicates that there was a tendency to over-estimate body weights. In addition, 18 animals did not show an adequate response to the first dose of drug they received and had to be topped up with a second dose. This fact, and the high dosage survived by all animals who received it at the top of the range, suggests that a somewhat higher initial dose would be appropriate.

The absence of any mechanical injuries is noteworthy, particularly in the case of immobilized animals falling out of trees. However, it has to be borne in mind that in secondary or logged-over forest there are few really high trees left (by rain-forest standards) and in these operations orang-utans seldom fell from more than $30 \mathrm{~m}$. It may not be appropriate to immobilize orang-utans in primary forest trees of twice this height or more.

It is difficult to know how to interpret the unbalanced sex ratio, in favour of females, of the captured animals, particularly because it is present in immature animals as well as adults. Were it not for the latter fact, one might postu- 
late that the greater number of the more mobile adult males, unencumbered by dependent young, had managed to escape from the pocketed groups to a distant forest containing the parent population. This would be a natural result of the greater ranging distances of the male orang-utan, known from studies of undisturbed populations.

The cost of the operation, at approximately \$US175 per animal, is modest and means that it is economically feasible to continue to carry out such rescue activities for beleaguered orang-utan groups whenever there is a need. There is, however, provision in Sabah's recently revised wildlife legislation for such costs to be borne by the plantation owner, whose clearing of the forest for commercial gain is the cause of pocketing and related conservation problems.

Regular monitoring of the translocated animals is the key to on-going evaluation of the operations reported and the nest index proposed for this has been used successfully by a number of orang-utan researchers (Rijksen 1978; Djojosudharmo and van Schaik, 1992). In this regard, there is as yet no established way for management staff (as opposed to full-time researchers) to readily identify wild orangutans individually. However, experiments with permanent freeze-branding, of a type reported for other species (Rood and Nellis, 1980), are currently being carried out as an approach to this recognition problem. The ultimate mark of success would be the proven breeding of the translocated orang-utans and their integration into the existing Tabin sector of the population.

In addition to dispersal patterns and food availability, the health and reproduction of the released animals will be monitored.
Introduction of new diseases into the resident population is unlikely. Until very recently forest cover between Tabin and the three capture areas was continuous, so that residents and released individuals are effectively members of the same population, with common disease characteristics.

\section{Acknowledgments}

We wish to thank our colleagues Jumrafiah Abdul Shukor, Dr Rika Akamatsu and Christovol Jomitin and their respective staff for support and assistance during the translocation operations. The work was often extremely demanding of the skill and resources of the rangers and labourers of the Wildlife Department and we wish to express our appreciation of all those who were involved. The co-operation of the management staff of the plantations involved is also acknowledged.

\section{References}

Caldecott, J. and Kavanagh, M. 1983. Can translocation help wild primates? Oryx 17, 135-139.

Djojosudharmo, S. and van Schaik, C.P. 1992. Why are orangutans so rare in the highlands? Tropical Biodiversity, 1, 11-22.

Payne, Junaidi. 1988. Orang-utan Conservation in Sabah. WWF Malaysia, Kuala Lumpur. 137 pp.

Rijksen, H.D. 1978. A field study of Sumatran orangutans (Pongo pygmaeus abelii) Lesson, 1827). Veenman en zonen, Wageningen.

Rood, J.P. and Nellis, D.W. 1980. Freeze marking mongooses. Journal of Wildlife Management, 44, 500-501.

Patrick Mahedi Andau, Lim Khun Hiong and John B. Sale ${ }^{1}$, Sabah Wildlife Department, 5th Floor, Block B, Wisma Muis, 88400, Kota Kinabalu, Sabah, Malaysia.

${ }^{1}$ Present address: 4 Waterperry Oxford OX33 1LD, UK. 